\title{
Rentabilidad de la innovación genética en maíz amarillo duro (Zea mays L. var indurata) y papa blanca (Solanum tuberosum) en el Perú
}

\author{
Ramón Alberto Diez Matallana, Raquel Margot Gómez Oscorima y Agapito Linares Salas \\ Universidad Nacional Agraria La Molina, Lima
}

Recibido: 12/7/2017 - Aprobado: 6/10/2017

Resumen: En el Perú la papa blanca y el maíz amarillo duro ocupan 600000 hectáreas y brindan sustento a 680000 productores. El maíz amarillo duro es la base de la industria avícola y los productores locales proveen solo el $40 \%$ del grano que usa esta industria (1,2 millones de toneladas). La papa es un alimento de alto consumo por los peruanos pues supera los 80 kilogramos por persona. Se maneja la hipótesis de que los agricultores paperos y maiceros logran bajos niveles de productividad por no usar semillas mejoradas genéticamente, disponibles en el mercado mundial.

Palabras clave: innovación tecnológica, rendimiento agrícola, presupuesto parcial

\section{Profitability of genetic innovation in hard yellow maize (Zea mays L. var indurata) and white potato (Solanum tuberosum) in Peru}

\begin{abstract}
In Peru, white potatoes and yellow corn occupy about 600,000 hectares and provide support to 680,000 producers. Yellow corn is the basis for the poultry industry, providing local farmers $40 \%$ of the grain that this industry requires (1.2 million tons), and potato is a highly demanded food by Peruvians (as much as 80 kilograms per person). Our hypothesis is that hard yellow corn and potato producers achieve low levels of productivity because they do not use genetically improved seeds available in the world market.
\end{abstract}

Keywords: technological innovation, agricultural output, partial budget 


\section{INTRODUCCIÓN}

Se evalúa el impacto en la rentabilidad para los agricultores de maíz y papa de una hipotética liberación de semillas mejoradas genéticamente de papa blanca y maíz amarillo duro. De acuerdo con la Ley 29811 (9 de diciembre del 2011), conocida como "Ley de moratoria" (medida temporal de suspensión y aplazamiento del procedimiento regular de autorización) al ingreso y producción de organismos vivos modificados en el territorio nacional hasta el 2021, el Perú no puede importar semillas ni producir organismos vivos modificados. Por esta razón, la evaluación no puede ser ex post, sobre datos observados, sino que debe hacerse ex ante, al contar solo con datos probabilísticos construidos a partir de la literatura para los posibles impactos en rendimiento de las semillas mejoradas y la opinión de expertos respecto a los cambios en el uso de pesticidas e incrementos en los costos de semillas, al usar semillas mejoradas genéticamente (Diez, Gómez y Varona, 2013). En la evaluación antes de la siembra de la semilla mejorada de alto rendimiento para estos cultivos se asume que su liberación afecta:

1. Los costos de semilla; la semilla genéticamente modificada se cotiza a mayores precios que la convencional debido a sus beneficios evidentes para los agricultores.

2. Reduce el uso de pesticidas (lo cual reduce los costos) y se mantienen constantes las demás variables (Diez et al., 2013).

Según Zevallos (2017), la papa y el maíz amarillo duro son cultivos de gran importancia en el Perú por el número de productores involucrados; en conjunto, 680000 unidades agrícolas; es decir, considerando una media de cinco personas por familia, algo más de tres millones de peruanos; por la superficie que ocupan (600 000 hectáreas); por su uso potencial como insumo para la industria (la papa puede ser fuente de almidón); por el alto nivel de consumo (85 kg per cápita, según http://rpp. pe/economia/economia/cuantos-kilos-de-papa-consume-un-peruano-enpromedio-cada-semana-noticia-808196), y por sus vinculaciones con la producción de alimentos balanceados para aves y cerdos (el maíz amarillo duro producido localmente cubre $40 \%$ de los requerimientos de la industria avícola). En el Perú el rendimiento por hectárea cultivada de maíz amarillo duro es inferior al de los Estados Unidos, Argentina y otros países, lo cual ocasiona que el país sea importador neto. El creciente rendimiento por hectárea de los últimos años no permite superar a los países que han aplicado innovaciones agrícolas como las semillas genéticamente modificadas. En el caso de la papa, los agricultores peruanos presentan 
alta probabilidad de rentabilidad negativa, oscilando de un margen bruto negativo de 23,1 \% (para Lima) a 45,7 \% (para Huánuco), según Minaya (2015). Para Zevallos (2017), los productores agrícolas y los tomadores de decisiones - a nivel nacional- desconocen la rentabilidad de los cultivos y no cuentan con información sobre cuál sería el impacto de nuevas semillas en los rendimientos agrícolas, especialmente en maíz amarillo duro y papa. En consecuencia, es necesario determinar el impacto en la rentabilidad de los agricultores de maíz amarillo duro y papa por la liberación de semillas genéticamente modificadas. Como objetivo general, se trata de evaluar ex ante el impacto de la aplicación de semillas mejoradas genéticamente sobre la rentabilidad de los cultivos de papa y maíz amarillo duro.

\section{IMPORTANCIA Y LOCALIZACIÓN DE LOS CULTIVOS}

Entre los cultivos transitorios más importantes por su participación respecto a la superficie sembrada total, están la papa y el maíz amarillo duro (13 y $14 \%$ respectivamente, según Zevallos, 2017). El maíz amarillo duro genera 79000 puestos de trabajo permanentes y su cultivo se realizaba en algo más de 293000 hectáreas en el 2013 (INEI, 2014); más del 60 \% en la costa. La producción del maíz amarillo duro llega a más de 1,4 millones de toneladas (Minagri, 2017) y constituye el primer eslabón de la cadena agroalimentaria que termina en las industrias de carne de ave y cerdo. Sin embargo, las importaciones de este producto ascienden a 3020 408,86 toneladas con un desembolso de divisas de USD 580362164 en el 2016. El precio a diciembre del 2016 era de USD 0,192 el kilogramo (Agrodata Perú).

Según Diez y Echevarría (2007), la papa ocupa a 600000 agricultores en 272000 hectáreas; en las que existen muchas parcelas con áreas menores a una hectárea. La mayoría cultiva variedades de papa blanca con una productividad promedio nacional de 13,59 t/ha, predominando el uso de semilla no certificada (Echevarría, 2014). Entre 1990 y el 2010, la producción de papa creció de más de un millón de toneladas a casi cuatro millones de toneladas, por la ampliación del área sembrada, la mejora en los rendimientos y por factores climáticos (Zevallos, 2017). La mejora de rendimientos (de 7,88 a 13,59 t/ha en el mismo periodo) fue inferior a lo que alcanzaron Colombia (16 t/ha), Brasil (15 t/ha), Chile (15 t/ha) y México (21 t/ha). La baja calidad de la semilla y la sanidad explicarían este bajo desempeño. 


\section{UNA VISIÓN DE LA RENTABILIDAD AGRÍCOLA EN DISTINTAS REGIONES DEL MUNDO}

En el documento de IICA (2015) que recoge las conclusiones del Encuentro de Ministros de Agricultura de las Américas 2015 y de la Decimoctava Reunión Ordinaria de la Junta Interamericana de Agricultura, se muestra que América Latina y el Caribe presentan una posición intermedia entre las diversas regiones del mundo en cuanto a su valor agregado agrícola (VAA). Esto señala que la región tiene aptitud para mejorar su productividad y rentabilidad, que lo ha venido logrando y que podría mejorar incorporando nuevas semillas y crianzas.

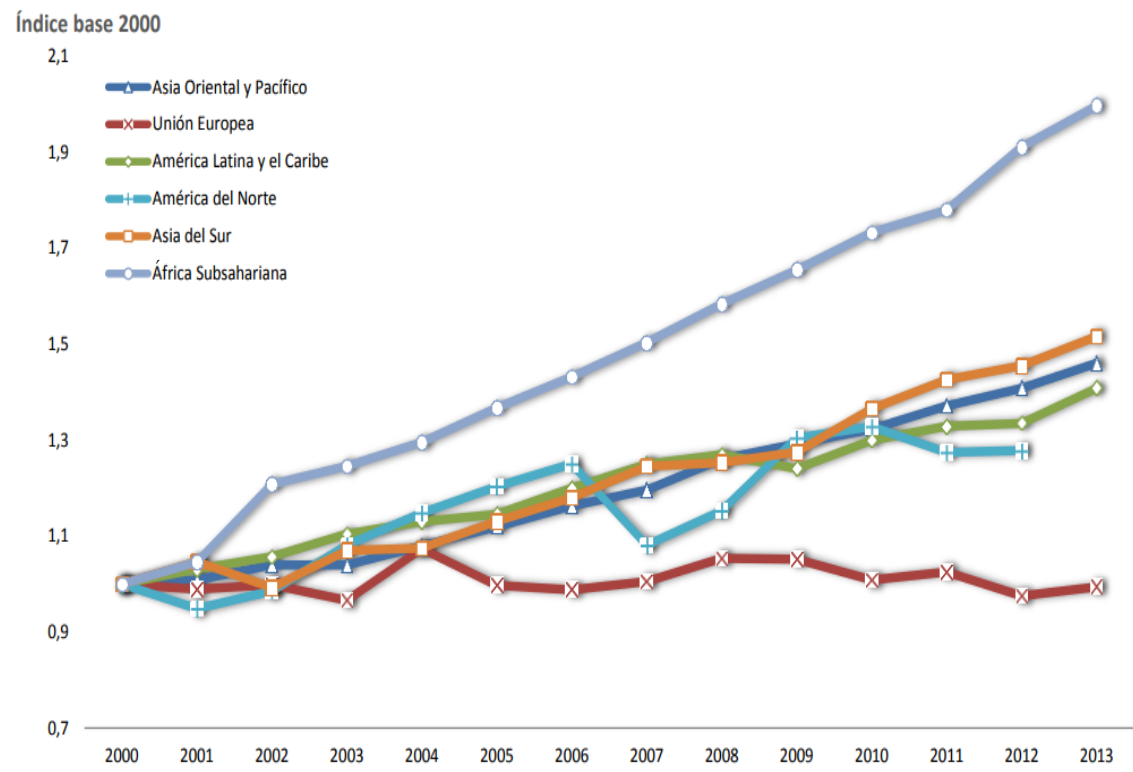

Figura 1. Evolución del valor agregado agrícola (VAA) en distintas regiones del mundo Fuente: IICA, 2015

\section{MEJORAMIENTO GENÉTICO CONVENCIONAL DE LA PAPA}

Según Egúsquiza y Apaza (2002), uno de los principales problemas de la producción de papa es la rancha, enfermedad muy frecuente que reduce hasta en un $40 \%$ la producción y que es generada por el oomyceto 
Phytophthora infestans. Que sigue siendo importante se evidencia comparando la publicación del diario Correo del 17 de enero del 2010 que informaba que "La rancha acecha cultivos de papa", y siete años después, el 6 de marzo del 2017, Agronoticias publicaba un suplemento especial titulado "Cómo prevenir, controlar y eliminar a la rancha de la papa".

En Huánuco (Luna, 2013), para evitar pérdidas, los agricultores aplican de 15 a 21 veces combinaciones de fungicidas, incrementando el costo de producción, con efectos adversos en la salud humana y el medio ambiente y creando condiciones para la aparición de nuevas variantes o razas más agresivas del parásito. Para hacer frente a esta enfermedad, el Centro Internacional de la Papa (CIP), mediante hibridación convencional, logró la variedad Canchán, con ayuda del Sistema Nacional de Evaluación de Recursos Genéticos (1984-1990), la cual a la fecha ha perdido resistencia.

\section{PRODUCTIVIDAD Y TECNOLOGÍA EN AGRICULTURA}

La tecnología agrícola, de acuerdo con Hayami y Ruttan (1985) puede ser mecánica (ahorradora de mano de obra), hidráulica, química o biológica (ahorradoras de tierra). La tecnología biológica lleva a la selección y el diseño de nuevas variedades de cultivos biológicamente eficientes, adaptados para responder a elementos no sujetos al control humano, y es importante en zonas donde la mecanización, el riego o las tecnologías químicas son difíciles de usar o encuentran límites naturales para hacer eficiente, competitiva y rentable la actividad agrícola. Según Diez et al. (2013), las semillas mejoradas genéticamente representan una estrategia para el aumento de la productividad en la agricultura, aunque hay reticencias por posibles impactos indeseables en el ambiente y en la salud de los usuarios, manteniéndose un debate abierto en las publicaciones científicas. Séralini (2014) muestra que existen posibles daños (cáncer) para los consumidores del maíz amarillo duro, mientras que otros científicos sostienen que no hay daños y que los trabajos de Séralini adolecen de vicios metodológicos (Zamora, 2012). Por otro lado, Jonathan Latham ${ }^{1}$, expresa dudas sobre los posibles daños derivados del uso de transgénicos,

$1 \mathrm{PhD}$, cofundador y director de Bioscience Resource Project; editor del sitio web Independent Science News. Máster en Crop Genetics y PhD en Virología. http:// cisgenesistransgenesisintragenesis.blogspot.pe/2015/11/aida-jonathan-latham-laexperien cia-de.html 
específicamente la soya y el maíz resistentes a herbicidas, y en especial al glufosinato ${ }^{2}$, también se preocupa por la semejanza entre Bacillus thurigiensis y Bacillus anthracis (bacteria que provoca el ántrax) y por el hecho que los insecticidas Bt son semejantes a la ricina, un peligroso veneno.

Dado que los aspectos de inocuidad biológica se mantienen bajo controversia, deben evaluarse las posibles consecuencias de cada semilla antes de su liberación en nuestro país, tal como establece el Protocolo de Cartagena sobre Seguridad de la Biotecnología del Convenio sobre la Diversidad Biológica (2000) y como ocurre en los otros países que han adoptado estas semillas. En cuanto a las implicancias económicas de las semillas mejoradas para el Perú, Mogollón (2015) señala que la productividad del maíz amarillo duro es inferior a la de otras regiones del mundo debido a la menor productividad de las semillas empleadas respecto a semillas genéticamente modificadas existentes. La investigación económica sobre el uso de semilla mejorada genéticamente en la producción agrícola, como muestran los trabajos de Luna (2013), Abad (2014) y Mogollón (2015), que prueban que la rentabilidad de papa y maíz genéticamente modificados, en diversos ámbitos del Perú, ayudará a los tomadores de decisiones a dictaminar si conviene o no liberarlas para incrementar la productividad de estos cultivos.

\section{ANÁLISIS ECONÓMICO DE LA RENTABILIDAD}

La empresa, del sector económico que sea, se rige por el principio de maximización de utilidades y minimización de pérdidas (Parkin, Esquivel y Loría, 2010). La rentabilidad se obtiene restando a los ingresos derivados de la venta del producto los costos fijos y variables. Según Minaya (2015) el indicador de la rentabilidad es el margen bruto por hectárea, porque en la producción agrícola existen problemas para medir la rentabilidad neta debido a las dificultades para obtener el valor del capital invertido y su respectivo costo de oportunidad, así como el monto de la renta de la tierra. La fórmula del margen bruto es: $\mathrm{Mb}=(\mathrm{P})(\mathrm{Q})-(\mathrm{Ci}+\mathrm{C} s+\mathrm{Cp}+\mathrm{Maq})$, donde:

- Mb: valor esperado del margen bruto por hectárea (soles/ha).

- P: valor esperado del precio en chacra del producto (soles/tonelada).

2 En su investigación, Latham solo considera la resistencia a insectos que provee el Bacillus thuringiensis al maíz amarillo duro y la resistencia a rancha que provee el material genético de papa silvestre a la papa comercial. 
- Q: valor esperado del rendimiento por hectárea (toneladas/ha).

- Ci: Costos que no varían con la nueva semilla (soles/ha): mano de obra, fertilizantes, maquinaria agrícola.

- $C S=f(C s)$ : valor esperado de los costos de semillas (soles/ha).

- $C p=f(C p)$ : valor esperado de los costos de pesticidas (soles/ha).

En el sector agrario la rentabilidad es el resultado económico final de un proceso productivo en el que intervienen factores que generan incertidumbre en los resultados, tal como señala Seiko (2012) en su análisis de las causas de la rápida adopción de maíz transgénico resistente a insectos en Brasil, debida a los beneficios económicos para los productores por:

1. Reducción de costos por la menor aplicación de insecticidas.

2. Aumento de ingresos generado por el aumento de productividad al reducir pérdidas por ataque de lepidópteros.

3. Beneficios que superan el mayor costo de la tecnología de la transgénesis.

Los ingresos y los costos dependen de las variaciones de variables críticas:

1. Precios del grano.

2. Precios de pesticidas.

3. Diferencial de precios de semillas transgénicas respecto a las semillas convencionales.

4. Rendimientos por hectárea, que pueden afectar los beneficios netos de los agricultores.

Por ello se emplean funciones de distribución de probabilidad de las variables críticas en la ecuación de las ganancias netas. Con el método de Monte Carlo se obtienen las medidas de tendencia central y la variabilidad de los beneficios netos; se realiza el análisis de sensibilidad de los beneficios netos en relación con las variables críticas y se mapea el riesgo de adoptantes de tecnología transgénica. En el caso específico de la papa, los daños económicos causados por la rancha bordean en Europa los mil millones de euros sobre una producción total de papa valorada en 6 mil millones de euros (Haverkort et al. 2007). Estas pérdidas, señalan los 
autores, podrían ser reducidas liberando papa cisgénica ${ }^{3}$. No está de más señalar la importancia de los resultados del proceso productivo para los agricultores de pequeño o mediano tamaño, entre los cuales la incapacidad de contratar seguros $\mathrm{u}$ obtener financiamiento para sobrellevar el mal resultado de una campaña agrícola o varias consecutivas, puede terminar empujándolos a la venta de su parcela o al empobrecimiento más extremo y hasta al suicidio. Esto ha sido contrarrestado en parte con los cultivos transgénicos en la India, tal como señalan Klümper y Qaim (2014), en sus trabajos sobre cultivos transgénicos y sus consecuencias para países en vías de desarrollo.

\section{METODOLOGÍA}

El ámbito del estudio es el Perú y los productos por estudiar el maíz amarillo duro (Zea mays L. var indurata) Bt y la papa (Solanum tuberosum) cisgénica.

El maíz amarillo duro representa 3 \% del valor bruto de la producción agropecuaria (VBPA). La producción nacional presenta una tendencia creciente debido al incremento de la productividad media y de las áreas sembradas, respondiendo a la demanda creciente de la industria de alimentos balanceados para aves y cerdos. Los principales productores son Lima, La Libertad, San Martín y Lambayeque. Las importaciones representan $60 \%$ del consumo aparente y el producto tiene una significativa participación en la estructura de costos de la avicultura (60\%) y porcicultura (67\%). (Huamanchumo, 2014). De acuerdo con el Ministerio de Agricultura (página web http://frenteweb.minagri.gob.pe/sisca/?mod=salida consultada el 18 de setiembre del 2017), en el 2015 se produjeron 1,44 millones de toneladas. Hay que considerar que la industria avícola en el país utiliza más de 4,45 millones de toneladas, de las cuales se importa el $67 \%$ (más de 3,02 millones de toneladas), con un gasto de más de 500 millones de dólares.

En cuanto a la papa, el Perú posee más de 3800 variedades y cuenta con sedes del Centro Internacional de la Papa (CIP) en Lima y Huancayo (Junín). La papa se cultiva en 19 de los 24 departamentos del Perú, desde el nivel del mar hasta los 4200 metros de altitud, concentrándose en las regiones Quechua y Suni. La mayor superficie cultivada con papa está en la sierra (95\%) y tiene

3 La cisgénesis es la modificación genética de un organismo receptor de un gen natural que proviene de otro organismo sexualmente compatible. La transgénesis implica incorporar material genético de una especie diferente, como el Bacillus thuringiensis al maíz amarillo duro, según Sánchez-Crespo (2015). 
un volumen de producción de 90 \%. En el 2015, la producción nacional fue de 4,7 millones de toneladas y provino principalmente de la sierra: Puno $(15,3 \%)$, Huánuco (13,3 \%), Junín y La Libertad (9,2 \%, respectivamente), Cusco (8,2 \%), Apurímac (7,4 \%), Cajamarca (7,1 \%) y Huancavelica (5,1 \%). La productividad de la sierra (14,3 t/ha) fue menor a la de la costa (25 t/ha) en Lima e Ica que en conjunto aportan un 3,9\% del total nacional.

\section{Hipótesis general}

Liberar semilla mejorada genéticamente aumentará la rentabilidad por hectárea de los cultivos de papa y maíz amarillo duro.

\section{Tratamiento de la información}

Se aplica el presupuesto parcial en entorno de riesgo, en modelos probabilísticos, con ayuda del software @Risk, y se obtiene el Beneficio Costo Marginal de la liberación de semillas mejoradas de maíz amarillo duro y papa. Se conoce el valor del incremento en la producción que se lograría al liberar las nuevas semillas, lo cual brinda una idea de cuáles serían las pérdidas para cada agricultor por no adoptar las nuevas semillas. Se utilizan como fuentes de datos publicaciones del Ministerio de Agricultura y Riego (Minagri) y otras entidades.

\section{El modelo de presupuesto parcial}

Se emplea una versión probabilística que recoge el entorno de riesgo de la producción agrícola, empleando la simulación de Montecarlo, estandarizada para la evaluación de estas innovaciones tecnológicas en el Perú. Se utiliza el boletín de evaluación ex ante de alternativas transgénicas en el cultivo de papa blanca comercial elaborado por Diez et al. (2013) que recoge las enseñanzas y experiencias de Seiko (2012) y que ha dado una base metodológica a una gama de investigaciones económicas, como las de Mogollón (2015) y Abad (2014) sobre el cultivo de maíz genéticamente modificado, o los trabajos de Echevarría (2014) y Luna (2013) sobre papa resistente a fungosas a partir de los principios diseñados por Horton (1982), que consideraba probabilidades del $100 \%$ para los valores de rendimientos, precios y costos en sus análisis de impactos económicos derivados de un cambio en una actividad, sin afectar el resto de la unidad agrícola. Al trabajar en entorno de riesgo se incorpora la posibilidad de que las variables explicativas de la rentabilidad no presenten un solo valor sino una 
gama de posibles valores, presentando una distribución de probabilidad y configurando un análisis con variables vectoriales en vez de variables de valores puntuales. El análisis de presupuesto parcial conduce a un coeficiente de Beneficio Costo Marginal; para obtenerlo se compara la suma de ingresos derivados de implementar la mejora tecnológica (ingreso nuevo) con los costos abandonados (los correspondientes a la producción con la semilla convencional), y los costos que resultan de la suma del ingreso abandonado (correspondiente a la producción con la semilla antigua) con los costos relacionados con el proceso productivo con la semilla Bt (costos nuevos), de la siguiente manera:

$$
\text { Ingreso nuevo + costos abandonados }
$$

Beneficio/costo marginal $=$

Ingreso abandonado + costos nuevos

Se denomina marginal porque evalúa un cambio en una pequeña área del proceso productivo. Dado que la actividad agrícola está sujeta a riesgos, con una alta variabilidad de los rendimientos (explicable por agentes bióticos y abióticos: clima, disposición de agua, etcétera), hay una alta variabilidad en los precios, tanto del producto como de las semillas y otros insumos, por lo cual es necesario hacer la evaluación de presupuesto parcial y obtener el coeficiente de beneficio - costo marginal en un ambiente probabilístico, aplicando simulaciones como el @Risk y otros que se acoplan a la hoja de cálculo Excel.

\section{Rentabilidad}

La rentabilidad es la obtención de un beneficio económico sobre los costos de producción en que incurre la unidad productiva (Parkin, Esquivel y Loría, 2010). La rentabilidad privada se calcula con base en los ingresos y costos monetarios.

\section{Modelos de análisis}

Evaluación ex ante estocástica con un modelo de presupuesto parcial en entorno @Risk, de impactos en la rentabilidad para cada cultivo de las nuevas semillas. El índice beneficio - costo marginal resulta de dividir la suma de los nuevos beneficios entre la suma de los nuevos costos. El modelo de análisis es el siguiente: 
$\Sigma$ nuevos beneficios

Beneficio/costo marginal $=$

\section{$\Sigma$ nuevos costos}

Los nuevos beneficios son la suma de ingresos obtenidos con la semilla modificada genéticamente y los costos abandonados al dejar de emplear la semilla convencional. Los nuevos costos son la suma de los costos de producción con la semilla modificada genéticamente y de los ingresos abandonados al dejar la semilla convencional. Los incrementos en ingresos son probabilísticos porque dependen de un rango de cambio en el rendimiento del cultivo, es decir, de los valores esperados de rendimiento, del precio del cultivo, los costos de semilla, pesticidas, entre otros.

\section{Alcances y limitaciones del trabajo}

Las limitaciones están referidas al manejo y acceso a la información utilizada, en su mayoría información secundaria. El hecho de trabajar con semillas híbridas en sus versiones convencionales y transgénica (semilla comercial, híbrida, a la cual se le añade material genético de otras especies) o cisgénica (semilla comercial híbrida a la que se le añade material genético de parientes silvestres) reduce la posibilidad de proyectar los resultados para un horizonte de tiempo amplio debido a la pérdida de vigor híbrido. Sin embargo, lo que queda como válido es la tendencia que se evidencia al comparar semillas convencionales con semillas genéticamente modificadas

\section{Evaluación con el software @Risk}

Utilizando el software @Risk (http://www.palisade-lta.com/risk/), versión 7.5 de prueba para académicos y profesionales, se obtienen múltiples posibles resultados de los cambios tecnológicos y el Beneficio Costo Marginal de la liberación de semillas mejoradas de maíz amarillo duro y papa. Este software provee hasta 100000 iteraciones y realiza análisis de riesgo con un máximo de 100 simulaciones simultáneas (10 millones de escenarios posibles). Estos escenarios surgen de los vectores de precios de los productos, de sus rendimientos, de los precios de los insumos (semillas, pesticidas, fertilizantes, etcétera), de las variaciones de las variables afectadas (gasto en semillas, gasto en agroquímicos, rendimientos por hectárea). 
Consideraciones para el análisis de pérdidas por el no uso de las nuevas semillas

Los pasos de la simulación son los siguientes:

1. Se establecen los presupuestos de producción de cada cultivo. Los ítems probabilísticos: las variables de entrada (precios del producto, precio de las semillas, rendimiento por hectárea, variaciones de costos en semillas, agroquímicos, etcétera) y se define su distribución de probabilidad, que puede ser generalmente normal, uniforme o triangular. Hay ítems de costos estándar (coeficientes de uso y precio del factor de producción) para el cultivo, que se denominan determinísticos y no constituyen variables de entrada o de riesgo para el cultivo. Los valores de las variables ligados con la liberación de la nueva semilla se determinan con base en datos históricos y opiniones de expertos.

2. Cambios que se dan en el presupuesto de cada cultivo al usar la semilla modificada genéticamente: en rendimiento por hectárea, en el costo de la semilla y en el uso de compuestos químicos. Los parámetros de los cambios probables se fundamentan en trabajos que señalan que los rendimientos pueden crecer entre 0 y $30 \%$ al emplear semillas genéticamente modificadas, y de expertos como Enrique Fernández Northcote y Marcel Gutiérrez, que señalan que los costos de semillas pueden crecer entre $10 \%$ y $75 \%$, mientras que las aplicaciones de agroquímicos pueden reducirse, disminuyendo el gasto por este concepto entre 0 y $100 \%$.

3. Se analizan los resultados de las salidas: incrementos de rentabilidad por cultivo.

4. Se evalúa el impacto para todo el país extrapolando los resultados por área cultivada de maíz y papa.

La información de la superficie cosechada es la que aporta el Ministerio de Agricultura. El diferencial de rendimiento es la diferencia entre el escenario base esperado (con semilla convencional) de cada cultivo y el escenario esperado con la nueva semilla. Se toman los precios esperados para cada cultivo. 


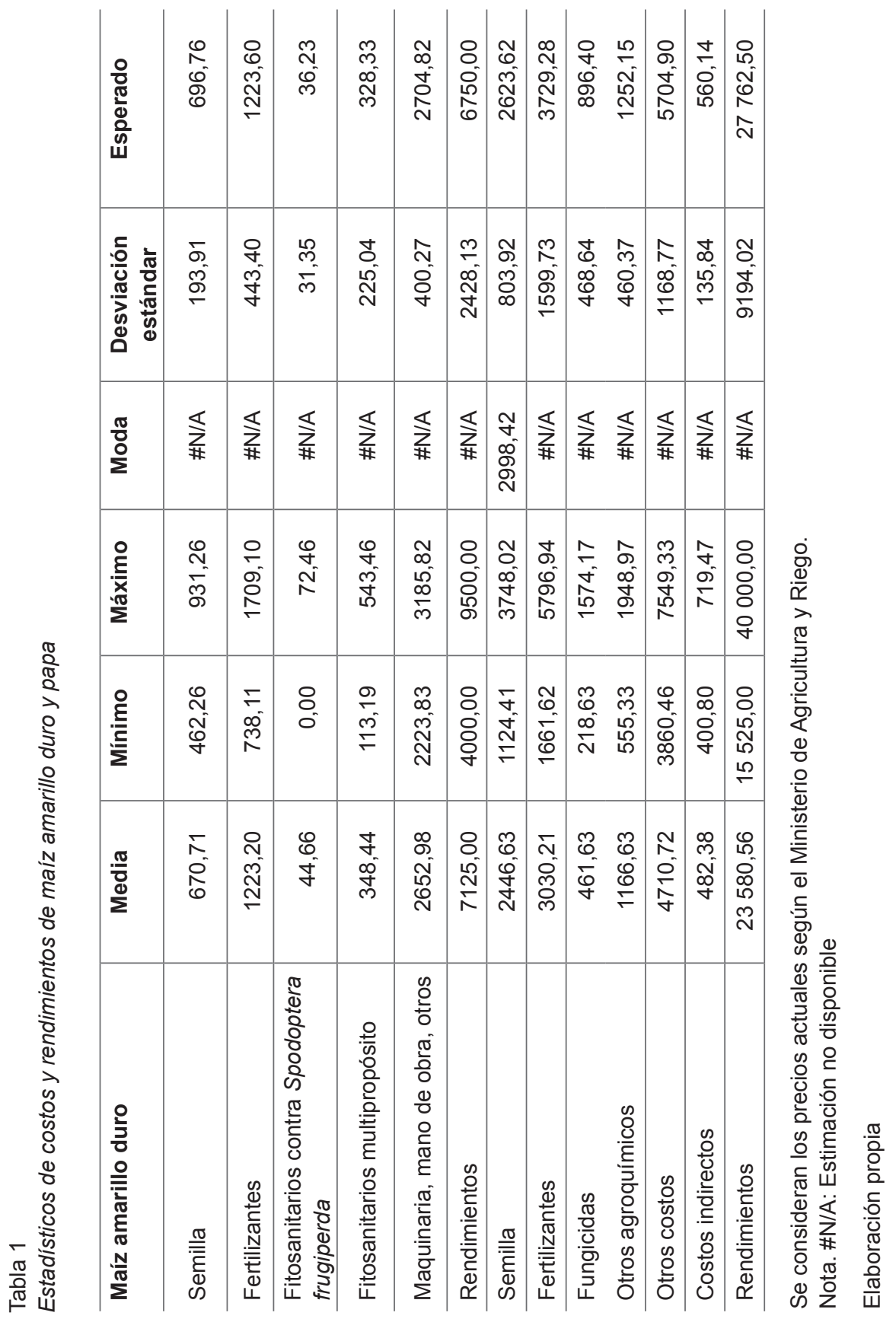


Tabla 2

Precios esperados de maíz y papa (S/ por kg) (octubre del 2016)

Estadísticos principales

\begin{tabular}{l|c|c|c}
\hline Concepto & Mínimo & Máximo & Esperado \\
\hline Precio de maíz & 0,98 & 1,43 & 1,21 \\
\hline Precio de papa & 1,16 & 2,56 & 1,86 \\
\hline
\end{tabular}

Elaboración propia, con datos del Ministerio de Agricultura y Riego (2017)

Tabla 3

Variaciones esperadas por uso de semillas genéticamente modificadas (porcentaje)

\begin{tabular}{l|c|c|c}
\hline Concepto & Mínimo & Máximo & Esperado \\
\hline Incremento en rendimiento & 0 & 30 & 15,0 \\
\hline Incremento en gasto en semilla & 10 & 75 & 42,5 \\
\hline Reducción de gasto en agroquímicos & 0 & 100 & 50,0 \\
\hline
\end{tabular}

Elaboración propia, con base en entrevistas a expertos

\section{RESULTADOS}

\section{Presupuestos de producción con las semillas genéticamente modificadas}

En la tabla 4, para los presupuestos de producción de maíz amarillo duro y papa blanca se presenta el efecto de la incorporación de semillas genéticamente modificadas. 
Tabla 4

Presupuesto parcial de los cultivos de maíz amarillo duro y papa blanca

\begin{tabular}{|c|c|c|}
\hline Maíz amarillo duro & Convencional & GM Bt \\
\hline Semilla & 696,76 & 975,46 \\
\hline Fertilizantes y otros & 1223,60 & 1223,60 \\
\hline Fitosanitarios contra Spodoptera frugiperda & 36,23 & 18,12 \\
\hline Otros fitosanitarios & 328,33 & 328,33 \\
\hline Total de insumos & 2284,92 & 2545,51 \\
\hline Maquinaria, mano de obra, otros & 2704,82 & 2704,82 \\
\hline Costos directos & 4989,74 & 5250,33 \\
\hline Costos indirectos & 1919,29 & 1919,29 \\
\hline Costo por hectárea & 6909,04 & 7169,63 \\
\hline Rendimiento $(\mathrm{kg} / \mathrm{ha})$ & 6750,00 & 7762,50 \\
\hline Precio (soles/kg) & 1,21 & 1,21 \\
\hline Ingresos & 8133,75 & 9353,81 \\
\hline Papa blanca & Convencional & Cisgénica \\
\hline Semilla & 2748,55 & 3847,97 \\
\hline Fertilizantes & 4215,28 & 4215,28 \\
\hline Fungicidas & 975,42 & 487,71 \\
\hline Otros agroquímicos & 1384,89 & 1384,89 \\
\hline Otros costos & 4760,83 & 4760,83 \\
\hline Costos directos & 14084,97 & 14696,68 \\
\hline Costos indirectos & 560,14 & 560,14 \\
\hline Costo por hectárea & 14645,11 & 15256,82 \\
\hline Rendimientos & 27762,50 & 31926,87 \\
\hline Precio esperado (soles/kg) & 1,86 & 1,86 \\
\hline Ingresos esperados & 51638,25 & 59383,99 \\
\hline
\end{tabular}

Elaboración propia con datos de Minagri e INEI. Los cambios considerados en gastos son las semillas modificadas (de mayor valor comercial por su mayor rendimiento por hectárea) y agroquímicos (en maíz amarillo duro se reducen los químicos para combatir Spodoptera frugiperda o gusano cogollero pues la proteína cry 1 del Bacillus thuringiensis en el maíz Bt los hace innecesarios; en papa se reduce el gasto en fungicidas pues con la semilla cisgénica no es necesario aplicarlos). También se considera la variación en el rendimiento por hectárea. 


\section{Indicadores de los cultivos analizados}

\section{Análisis de las variaciones de los cultivos}

En el maíz amarillo duro la semilla mejorada genéticamente generaría un incremento en el rendimiento que se traduciría en una mejora de la rentabilidad (S/ 959,47/ha), y el Beneficio Costo Marginal lograría un valor medio esperado de 1,06.

En el caso de la papa, la semilla cisgénica incrementa el rendimiento $\mathrm{y}$, junto con la reducción de fungicidas, compensa el mayor costo de la semilla, lo que mejora la rentabilidad en S/ 7134,03/ha y logra un Beneficio Costo Marginal medio de 1,10.

Tabla 5

Análisis de Beneficio Costo Marginal

\begin{tabular}{l|c|c}
\hline \multicolumn{1}{c|}{ Caso } & Maíz amarillo duro Bt & Papa cisgénica \\
\hline Nuevos beneficios & 16262,85 & 74029,10 \\
\hline Ingresos nuevos & 9353,81 & 59383,99 \\
\hline Costos abandonados & 6909,04 & 14645,11 \\
\hline Nuevos costos & 15303,38 & 66895,07 \\
\hline Costos con la semilla Bt & 7169,63 & 15256,82 \\
\hline Ingresos abandonados & 8133,75 & 51638,25 \\
\hline Beneficio Costo Marginal & 1,06 & 1,10 \\
\hline
\end{tabular}

Elaboración propia 

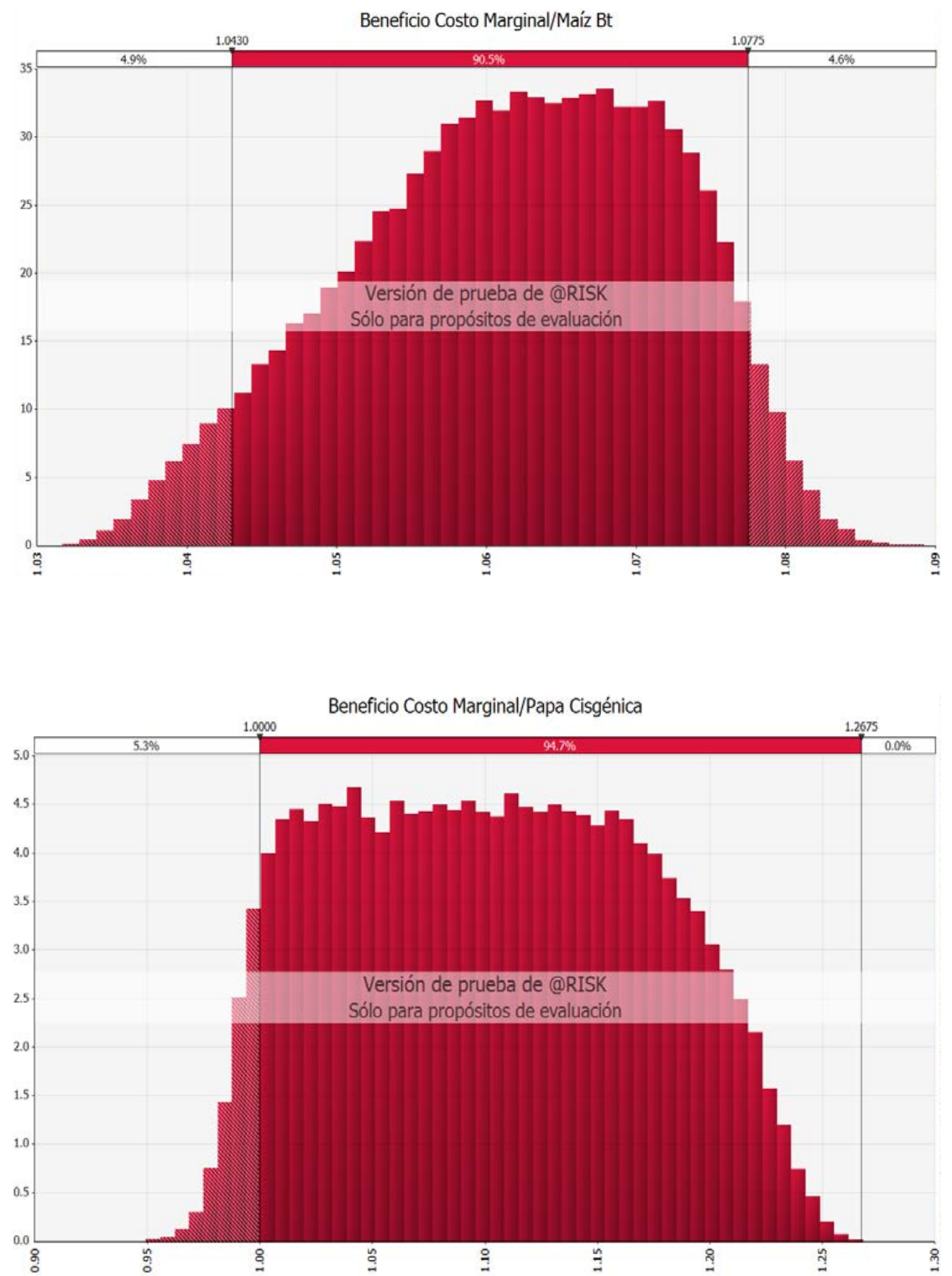

Figura 2. Resultados del cálculo de Beneficio Costo Marginal de maíz amarillo duro Bt y papa cisgénica

Elaboración propia 
Cabe señalar que en el caso del maíz amarillo duro se obtiene un $100 \%$ de escenarios positivos, es decir, el Beneficio Costo Marginal siempre es superior a 1. En el caso de la papa se obtiene solo un $94,7 \%$ de escenarios en los que el Beneficio Costo Marginal supera a 1.

\section{Análisis de pérdidas por no liberar las nuevas semillas}

Para evaluar las pérdidas para la agricultura nacional de papa y maíz amarillo duro por no emplear las nuevas semillas se considera la superficie de producción involucrada para un análisis de estática comparativa entre la producción total actual contra la producción total al aplicarse las nuevas semillas en cada cultivo.

Tabla 6

Pérdidas de rentabilidad en papa y maíz por no emplear semillas genéticamente modificadas

\begin{tabular}{lcccc}
\hline $\begin{array}{c}\text { Cultivos } \\
\text { agrícolas }\end{array}$ & $\begin{array}{c}\text { Superficie } \\
\text { (hectáreas) }\end{array}$ & $\begin{array}{c}\text { Pérdidas de } \\
\text { rentabilidad/ha } \\
(\mathrm{S} /)\end{array}$ & \multicolumn{2}{c}{$\begin{array}{c}\text { Pérdidas de rentabilidad } \\
\text { agrícola nacional }\end{array}$} \\
\hline $\begin{array}{l}\text { Maíz } \\
\text { amarillo } \\
\text { duro }\end{array}$ & 282597,75 & 942,05 & 266221775,58 & USD \\
$\begin{array}{l}\text { Papa } \\
\text { Total }\end{array}$ & 262658,50 & 7078,90 & 1859333365,09 & 575645004,67 \\
\hline
\end{tabular}

Tipo de cambio: USD $1=\mathrm{S} / 3,23$

Elaboración propia 


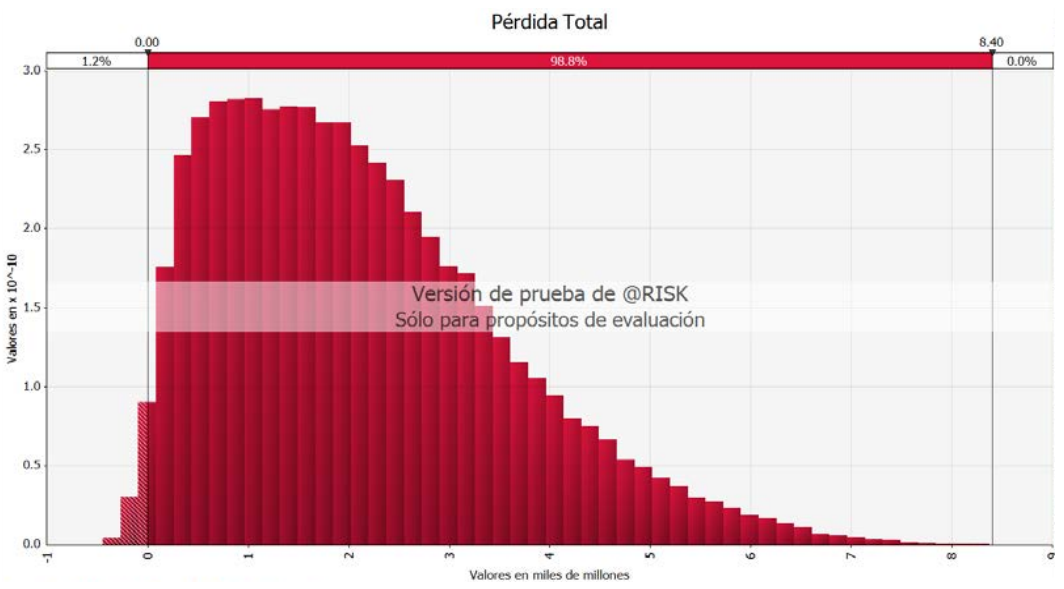

Figura 3. Pérdidas anuales por no usar semillas genéticamente modificadas (S/) Elaboración propia

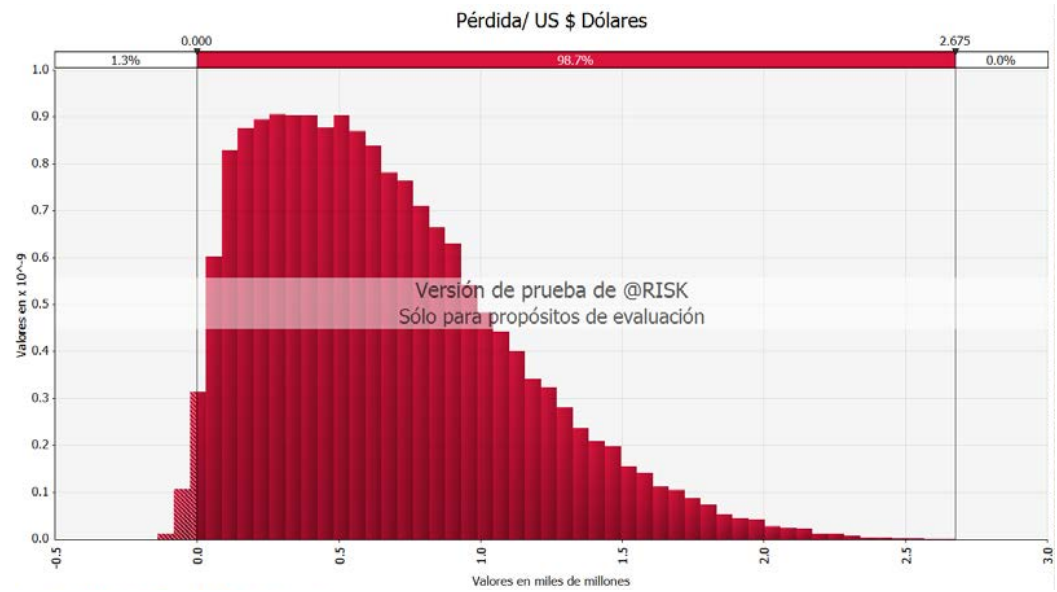

Figura 4. Pérdidas anuales por no usar semillas genéticamente modificadas (USD)

Elaboración propia 
No usar semillas mejoradas genéticamente cuesta más de 2125 millones de soles por año (USD 658 millones) en ambos cultivos. Se puede calcular también el monto que se ahorraría en divisas al emplear semillas modificadas genéticamente en el maíz amarillo duro.

Tabla 7

Ahorro esperado en divisas con el uso de semilla genéticamente modificada de maíz amarillo duro

\begin{tabular}{lr}
\hline Esperado de producción (t) & 1296400,50 \\
Producción esperada con semila genéticamente & \\
modificada (t) & 1490860,58 \\
Reducción de importaciones (t) & 194460,08 \\
Precio CIF USD/t & 184,40 \\
Ahorro en divisas (USD) & 35858437,83 \\
\hline
\end{tabular}

Elaboración propia

Como se ve, si se emplea la semilla de maíz amarillo duro Bt, se podrían reducir importaciones por un valor esperado medio de USD 35,8 millones (con un mínimo de USD 598 y un máximo de USD 71 millones) lo cual está asociado con una reducción esperada media de las importaciones anuales de 194000 toneladas.

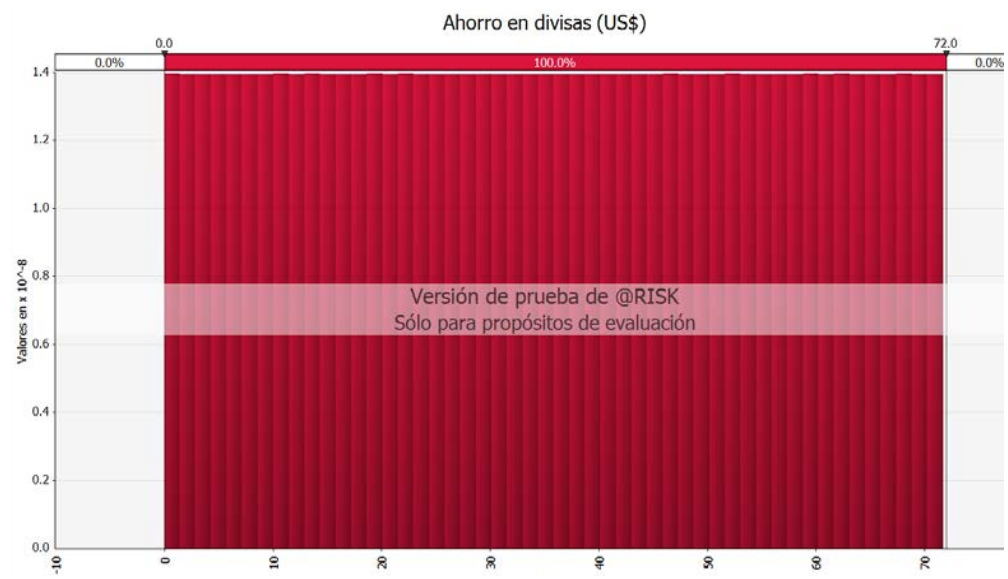

Figura 5. Ahorro en divisas derivado del uso de semilla de maíz amarillo duro Bt (USD)

Elaboración propia 


\section{DISCUSIÓN}

Los resultados se acercan a los obtenidos por Zevallos (2017), Mogollón (2015), Luna (2013), Diez et al. (2013) en cuanto a los beneficios a corto plazo para los productores peruanos de maíz amarillo duro y papa, obtenidos al liberar semillas genéticamente modificadas (maíz amarillo duro Bt o papa cisgénica). No ha sido posible comparar con resultados de investigaciones contrarias a este tipo de desarrollo genético porque esa línea de investigación ha privilegiado aspectos biológicos y no ha producido análisis económicos.

La metodología empleada por los autores mencionados se alinea con la de Seiko (2012) y guía el presente trabajo. La evidencia de la siembra real de alternativas transgénicas por agricultores de otros países permite establecer marcos de incremento en rendimientos de papa y maíz; calcular reducciones de gastos en agroquímicos y analizar criterios sobre los mayores costos de las semillas genéticamente modificadas. La información real de otros países ha sido matizada gracias a la información aportada por Fernández Northcote y Marcel Gutiérrez.

\section{CONCLUSIONES Y RECOMENDACIONES}

\section{Conclusiones}

1. Hay una brecha de productividad que puede y debe cubrirse empleando innovaciones tecnológicas. De acuerdo con los resultados de esta investigación esto es económicamente factible.

2. Los incrementos en rentabilidad por el uso de las nuevas semillas disponibles en el mercado mundial varían de S/ 959 (maíz amarillo duro) a S/ 7000 (papa) por hectárea en promedio, y los coeficientes de beneficio - costo al emplear las semillas de alto rendimiento varían entre 1,06 (maíz) y 1,11 (papa). Por tanto, es conveniente y viable para cada unidad productiva emplear dichas semillas.

3. La información procede de experiencias de otros lugares del mundo donde se utilizan estas semillas de alto rendimiento, demostrando su viabilidad.

4. A nivel nacional, los incrementos en rendimiento derivados de la implementación de nuevas tecnologías en los productos emblemáticos del país, generarían beneficios (o pérdidas por no implementarlas) por S/ 2134 millones (USD 637 millones) por año. 


\section{Recomendaciones}

1. Se debe investigar más sobre las nuevas tecnologías, en especial las de mayor impacto y fácil aplicación, como las biológicas (nuevas semillas), en cuanto a su impacto genético sobre otras especies y su rentabilidad económica y social.

2. La moratoria para la importación o producción de semillas transgénicas en el Perú concluirá en el 2021. El Estado debe contar con información científica sobre las ventajas y desventajas técnicas y económicas de las semillas genéticamente modificadas para los principales centros de producción de cada producto agrícola, dado que es necesario hacer una evaluación caso por caso y cultivo por cultivo.

\section{REFERENCIAS}

Abad, R. (2014). Rentabilidad del maíz Bt resistente a cogollero (Spodoptera frugiperda) en los Valles de Barranca en la región Lima. Tesis para optar el título de economista. Universidad Nacional Agraria La Molina. Lima.

Agrodata Perú, página web especializada en Comercio Internacional, dirigida por Wilfredo Koo Gallo. Recuperado de https://www. agrodataperu.com/ category/importaciones/maiz-amarillo-duro

Agronoticias (2017). Cómo prevenir, controlar y eliminar a la rancha de la papa (6 de marzo).

Diario Correo (2010). La rancha acecha cultivos de papa. 17 de enero del 2010.

Diario oficial El Peruano (s/f). Ley 29811, Ley que establece la moratoria al ingreso y producción de organismos vivos modificados al territorio nacional por un periodo de 10 años.

Diez, R., Gómez, R., Navarro, O., Varona, A. y Anderson, M. (2013). Evaluación ex ante de alternativas transgénicas en el cultivo de papa blanca comercial. Proyecto LAC-Biosafety, América Latina: Construcción de capacidad multipaís para el cumplimiento del Protocolo de Cartagena sobre Bioseguridad (Brasil, Colombia, Costa Rica, Perú). Lima: Universidad Nacional Agraria La Molina, Instituto de Biotecnología.

Diez, R., Gómez, R. y Varona, A. (2013). Análisis de metodologías de evaluación antes y después de cambios tecnológicos: el caso de la 
liberación de los organismos genéticamente modificados en el Perú. Fórum Empresarial, 18(1).

Diez, R. y Echevarría, N. (2007). Impacto económico del uso de semilla certificada de papa (Solanum tuberosum L.) cultivar Canchán, distrito de Huasahuasi, provincia de Tarma, región Junín, campaña agrícola 2006-2007. Anales Científicos, Revista de la Universidad Nacional Agraria La Molina (en prensa).

Echevarría, A. (2014). Análisis ex ante de impactos económicos por la liberación de semilla cisgénica de papa (Solanum tuberosum) canchán en el distrito de Sicaya, provincia de Huancayo, región Junín. Tesis para optar el título de economista. Universidad Nacional Agraria La Molina. Lima.

Egúsquiza, R. y Apaza, T. (2002). La rancha de la papa (Phytophthora infestans) en el Perú, perfil de país. En: Fernández-Northcote, E. N. (ed.), Memorias del Taller Internacional Complementando la resistencia al tizón (Phytophthora infestans) en los Andes. Lima: GILB, Taller Latinoamérica 1 (29-39).

Haverkort, A., Boonekamp, P., Hutten, R., Jacobsen, E., Lotz, L., Kessel, G., Visser, R. y Van der Vossen, E. (2007). Societal cost of Late Blight in potato and prospects of durable resistance through cisgenic modification. Wageningen University and Research Centre.

Hayami, Y. y Ruttan, V. (1985). Agricultural Development: An International Perspective (2. ${ }^{a}$ edición). Baltimore: The Johns Hopkins University Press.

Horton, D. (1982). Análisis de presupuesto parcial para investigación en papa al nivel de finca. Boletín de Información Técnica, 16. Lima: Centro Internacional de la Papa.

Huamanchumo, C. (2013). La cadena de valor de maíz en el Perú: diagnóstico del estado actual, tendencias y perspectivas. Lima: Instituto Interamericano de Cooperación para la Agricultura (IICA).

Instituto Interamericano de Cooperación para la Agricultura (2015). Una productividad competitiva, incluyente y sustentable: oportunidad para el continente americano. Cancún: IICA.

Instituto Nacional de Estadística e Informática (2014). Compendio estadístico Perú 2014. Lima: INEI. 
Klümper, W. y Qaim, M. (2014). Meta-análisis de los impactos de cultivos genéticamente modificados. En: PLoS ONE. Band. 9, n. ${ }^{11}$, 3 de noviembre del 2014 (e111629). doi : 10.1371/journal.pone.0111629.

Luna, H. (2013). Efectos económicos de la liberación de papa genéticamente modificada resistente a fungosas en la localidad de Mayobamba, región Huánuco. Tesis para optar el título de economista. Universidad Nacional Agraria La Molina. Lima.

Minaya, C. (2015). Análisis de la rentabilidad en la producción de papa blanca comercial en las regiones de Huánuco y Lima. Anales Científicos, 76(2): 369-375. Universidad Nacional Agraria La Molina. Lima.

Ministerio de Agricultura y Riego (2017). Recuperado de http://frenteweb. minagri.gob.pe/sisca/?mod=salida

Mogollón, R. (2015). Rentabilidad del maíz amarillo duro (Zea mays) resistente al gusano cogollero (Spodoptera frugiperda) en el distrito de Jayanca, departamento de Lambayeque. Tesis para optar el título de economista. Universidad Nacional Agraria La Molina. Lima.

Parkin, M., Esquivel, G. y Loría, E. (2010). Microeconomía, Versión para Latinoamérica (9. ${ }^{a}$ edición). México: Pearson Educación.

Protocolo de Cartagena sobre bioseguridad en la Convención sobre diversidad biológica. Recuperado de http://bch.cbd.int/ protocol/ background/

Sánchez-Crespo, Diego (2015). Intragénesis y cisgénesis, desarrollo alternativo al cultivo de transgénicos. Facultad de Ciencias de la Universidad de Córdoba. Recuperado de https:/es.slideshare.net/ b02sasad/intragnesis-y-cisgnesis? from_action=save

Seiko, M. (2012). Dimensionamento de retornos econômicos e de riscos na adoção de milho RI no estado de São Paulo. Botucatu: Universidade Estadual Paulista (UNESP), Faculdade de Ciências Agronômicas (FCA).

Séralini, Gilles Eric, (2014). Long term toxicity of a Roundup herbicide and a Roundup-tolerant genetically modified maize. Environmental Sciences Europe (publicado en el 2012 por Food and Chemical Toxicology).

Zamora, Alfredo (2012). Inexactitudes científicas del estudio de Seralini sobre maíz modificado genéticamente. Fundación Antama. Recuperado de: http:/fundacion-antama.org/inexactitudes-cientificas-del-estudiode-seralini-sobre-el-maiz-modificado-geneticamente/ 
Zevallos, R. (2017). Impacto de la aplicación de alternativas tecnológicas sobre el rendimiento de los principales productos agrarios en el Perú. Tesis para optar el diploma de Magister Scientiae en Economía Agrícola. Universidad Nacional Agraria La Molina. Lima.

\section{BIBLIOGRAFÍA}

Alston, J., Norton, G. y Pardey, P. (1995). Science under scarcity. Principles and practice for agricultural research evaluation and priority setting. Nueva York: Cornell University Press.

Bernanke, B. y Frank, R. (2007). Principios de economía. Madrid: McGraw Hill/ Interamericana de España S.A.V.

Devaux, A., Ordinola, M., Hibon, A. y Flores, R. (2010). El sector papa en la región andina. Lima: Centro Internacional de la Papa.

Ludeña, C. (2010). Crecimiento de la productividad agrícola, cambio en la eficacia y el progreso técnico en América Latina y el Caribe. Serie Documento de Trabajo 186. Banco Interamericano de Desarrollo BID.

Ministerio de Agricultura (2004). Diagnóstico de la cadena MAD, avicultura y porcicultura. Lima: MINAG, Dirección General de Planificación Agraria.

Ministerio de Agricultura (2012). Maíz amarillo duro: Principales aspectos de la cadena agroproductiva. Lima: MINAG.

Radio Programas del Perú. Recuperado de http://rpp.pe/economia/economia/ cuantos-kilos-de-papa-consume-un-peruano-en-promedio-cadasemana-noticia-808196 


\section{Anexos}

\section{ANEXO 1}

\section{Costos de producción}

Cultivo de maíz amarillo duro (S/)

\begin{tabular}{|c|c|c|c|c|}
\hline Componentes & Lambayeque & La Libertad & Lima & San Martín \\
\hline Semilla & 370,00 & 510,00 & 522,00 & 745,40 \\
\hline Fertilizantes y otros & 784,00 & 1173,50 & 1368,00 & 590,80 \\
\hline $\begin{array}{l}\text { Fitosanitarios } \\
\text { contra Spodoptera } \\
\text { frugiperda }\end{array}$ & 46,00 & 39,00 & 58,00 & - \\
\hline $\begin{array}{l}\text { Fitosanitarios } \\
\text { multipropósito }\end{array}$ & 159,00 & 431,00 & 435,00 & 90,60 \\
\hline Total de insumos & 1361,00 & 2153,50 & 2383,00 & 1426,80 \\
\hline $\begin{array}{l}\text { Maquinaria, mano de } \\
\text { obra, otros }\end{array}$ & 2034,00 & 2130,00 & 2550,00 & 1780,00 \\
\hline Costos directos & 3395,00 & 4283,50 & 4933,00 & 3206,80 \\
\hline Costos indirectos & 1596,00 & 1946,22 & 1856,34 & 1126,27 \\
\hline Costo por hectárea & 4991,00 & 6229,72 & 6789,34 & 4333,07 \\
\hline Rendimiento $(\mathrm{kg} / \mathrm{h})$ & 6500,00 & 8500,00 & 9500,00 & 4000,00 \\
\hline \multicolumn{5}{|l|}{ Cultivo de papa (S/) } \\
\hline $\begin{array}{l}\text { Componentes } \\
\text { de los costos }\end{array}$ & $\begin{array}{l}\text { La Libertad } \\
\text { Otuzco }\end{array}$ & $\begin{array}{l}\text { La Libertad } \\
\text { Agallpampa }\end{array}$ & Lima Pativilca & Junín \\
\hline Semilla & 2400,00 & 1800,00 & 3000,00 & 1800,00 \\
\hline Fertilizantes & 4640,00 & 2162,00 & 2108,00 & 3892,00 \\
\hline Fungicidas & 475,00 & 1260,00 & 379,00 & 301,50 \\
\hline Otros agroquímicos & 1560,00 & 710,00 & 657,00 & 989,00 \\
\hline Maquinaria & 930,00 & 780,00 & 745,00 & 490,00 \\
\hline Mano de obra & 1656,00 & 1602,00 & 2314,00 & 2160,00 \\
\hline Otros gastos directos & 1344,09 & 1094,34 & 857,00 & 1495,00 \\
\hline Costos directos & 13005,09 & 9408,34 & 10060,00 & 11127,50 \\
\hline Costos indirectos & 565,52 & 320,81 & 463,55 & 575,88 \\
\hline Costo por hectárea & 13570,61 & 9729,15 & 10523,55 & 11703,38 \\
\hline
\end{tabular}


(continuación)

\begin{tabular}{lrrrr}
\hline Componentes & Huasahuasi & Valle Majes & Pucuhuillca & Huánuco \\
\hline Semilla & 1875,00 & 2400,00 & 2250,00 & 900,00 \\
Fertilizantes & 1549,00 & 1614,00 & 1974,00 & 2560,00 \\
Fungicidas & 322,50 & 187,50 & 105,00 & 120,00 \\
Otros agroquímicos & 444,50 & 714,70 & 1259,00 & 1470,00 \\
Maquinaria & 350,00 & 1200,00 & 600,00 & 1215,00 \\
Mano de obra & 1824,00 & 3510,00 & 1275,00 & 114,00 \\
Otros gastos & 916,00 & 1332,65 & 2094,00 & 0,00 \\
directos & 7281,00 & 10958,85 & 9557,00 & 6379,00 \\
Costos Directos & 365,18 & 547,94 & 277,71 & 0,00 \\
Costos indirectos & 7646,18 & 11506,79 & 9834,71 & 6379,00 \\
Costo por hectárea & & &
\end{tabular}

Fuente: Ministerio de Agricultura (2009)

Elaboración propia 


\section{ANEXO 2}

\section{Costos de producción actualizados al 2016}

Costos de producción por regiones del cultivo de papa actualizado a octubre del 2016 (S/)

\begin{tabular}{|c|c|c|c|c|c|}
\hline $\begin{array}{l}\text { Componentes } \\
\text { de los costos }\end{array}$ & $\begin{array}{l}\text { La Libertad } \\
\text { Otuzco }\end{array}$ & $\begin{array}{l}\text { La Libertad } \\
\text { Agallpampa }\end{array}$ & $\begin{array}{c}\text { Lima } \\
\text { Pativilca }\end{array}$ & Junín & \\
\hline Semilla & 2998,42 & 2248,81 & 3748,02 & 2248,81 & \\
\hline Fertilizantes & 5796,94 & 2701,08 & 2633,61 & 4862,44 & \\
\hline Fungicidas & 593,44 & 1574,17 & 473,50 & 376,68 & \\
\hline $\begin{array}{l}\text { Otros } \\
\text { agroquímicos }\end{array}$ & 1948,97 & 887,03 & 820,82 & 1235,60 & \\
\hline Otros costos & 4910,02 & 4343,14 & 4892,42 & 5178,52 & \\
\hline Costos directos & 16247,80 & 11754,23 & 12568,37 & 13902,04 & \\
\hline Costos indirectos & 706,53 & 400,80 & 579,13 & 719,47 & \\
\hline Costo por hectárea & 16954,32 & 12155,03 & 13147,51 & 14621,52 & \\
\hline Rendimientos & 15525,00 & 20700,00 & 40000,00 & 25000,00 & \\
\hline $\begin{array}{l}\text { Componentes } \\
\text { de los costos }\end{array}$ & Cajamarca & $\begin{array}{c}\text { Junín } \\
\text { Huasahuasi }\end{array}$ & $\begin{array}{l}\text { Arequipa } \\
\text { Valle } \\
\text { Majes }\end{array}$ & $\begin{array}{l}\text { Ayacucho } \\
\text { Pucuhuillca }\end{array}$ & Huánuco \\
\hline Semilla & 1499,21 & 2342,51 & 2998,42 & 2811,02 & 1124,41 \\
\hline Fertilizantes & 1661,62 & 1935,23 & 2016,44 & 2466,20 & 3198,31 \\
\hline Fungicidas & 218,63 & 402,91 & 234,25 & 131,18 & 149,92 \\
\hline $\begin{array}{l}\text { Otros } \\
\text { agroquímicos }\end{array}$ & 749,60 & 555,33 & 892,90 & 1572,92 & 1836,53 \\
\hline Otros costos & 5043,59 & 3860,46 & 7549,33 & 4958,64 & 1660,37 \\
\hline Costos directos & 9172,66 & 9096,45 & 13691,34 & 11939,95 & 7969,55 \\
\hline Costos indirectos & 447,70 & 456,23 & 684,56 & 346,95 & 0,00 \\
\hline Costo por hectárea & 9620,37 & 9552,69 & 14375,91 & 12286,91 & 7969,55 \\
\hline Rendimientos & 20000,00 & 18000,00 & 35000,00 & 18000,00 & 20000,00 \\
\hline
\end{tabular}

Fuentes: Ministerio de Agricultura (2009) e INEI (2016)

Elaboración propia 


\section{ANEXO 3}

\section{Variables de salida de análisis de impacto de innovación tecnológica}

\section{Informe @RISK Salida para Beneficio Costo Marginal/Maíz Bt B12}

Ejecutado por: Diez, Gómez y Linares

Fecha: viernes, 22 de septiembre de 2017 12:05:04 p.m.

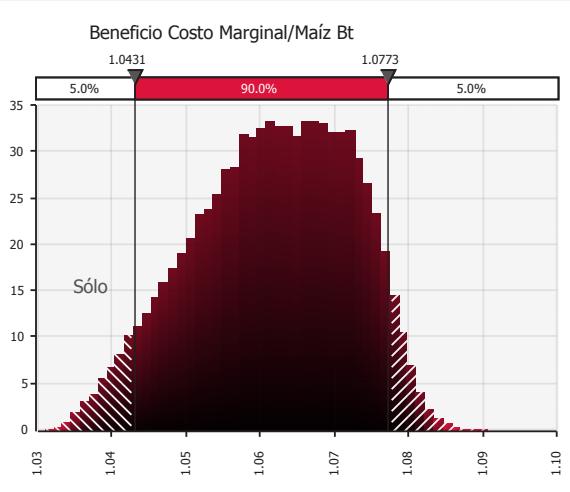

\begin{tabular}{l|l} 
Información de resumen de simulación \\
\hline Nombre de libro de trabajo & Libro1 \\
\hline Número de simulaciones & 1 \\
\hline Número de iteraciones & 100000 \\
\hline Número de entradas & 19 \\
\hline Número de salidas & 2 \\
\hline Tipo de muestreo & Latino Hipercúbico \\
\hline Tiempo de inicio de simulación & $22 / 09 / 2017$ 12:01 \\
\hline & $22 / 09 / 2017$ 12:01 \\
\hline Duración de simulación & $00: 00: 15$ \\
\hline Generador de \# aleatorio & Mersenne Twister \\
\hline Semilla aleatoria & 670979581 \\
\hline Total de errores & 0 \\
\hline Recolectar muestras de distribucic Todos \\
\hline Convergencia & Inhabilitado \\
\hline Análisis de sensibilidad inteligent & Habilitado \\
\hline
\end{tabular}

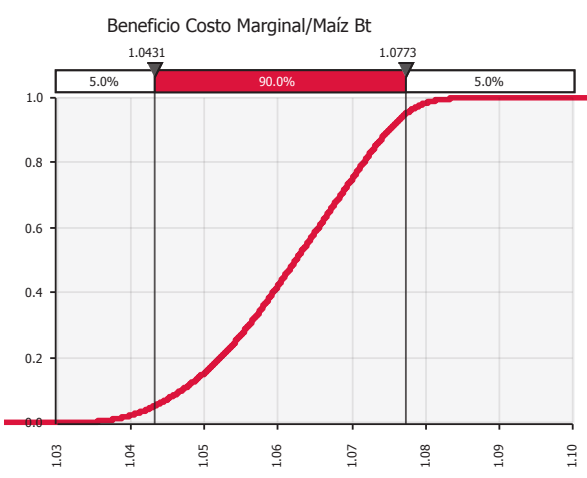

\begin{tabular}{|c|c|c|c|}
\hline \multicolumn{4}{|c|}{ Estadísticos resumen para Beneficio Costo Marginal/Maíz E } \\
\hline \multicolumn{2}{|l|}{ Estadísticos } & \multicolumn{2}{|l|}{ Percentil } \\
\hline Mínimo & 1.03 & $1.0 \%$ & 1.04 \\
\hline Máximo & 1.09 & $2.5 \%$ & 1.04 \\
\hline Media & 1.06 & $5.0 \%$ & 1.04 \\
\hline Desv Est & 0.01 & $10.0 \%$ & 1.05 \\
\hline Varianza & 0.000110374 & $20.0 \%$ & 1.05 \\
\hline Indice de sesgo & -0.27609251 & $25.0 \%$ & 1.05 \\
\hline Curtosis & 2.36307287 & $50.0 \%$ & 1.06 \\
\hline Mediana & 1.06 & $75.0 \%$ & 1.07 \\
\hline Moda & 1.07 & $80.0 \%$ & 1.07 \\
\hline $\mathrm{X}$ izquierda & 1.04 & $90.0 \%$ & 1.07 \\
\hline P izquierda & $5 \%$ & $95.0 \%$ & 1.08 \\
\hline $\mathrm{X}$ derecha & 1.08 & 97.5\% & 1.08 \\
\hline P derecha & $95 \%$ & $99.0 \%$ & 1.08 \\
\hline \#Errores & 0 & & \\
\hline
\end{tabular}

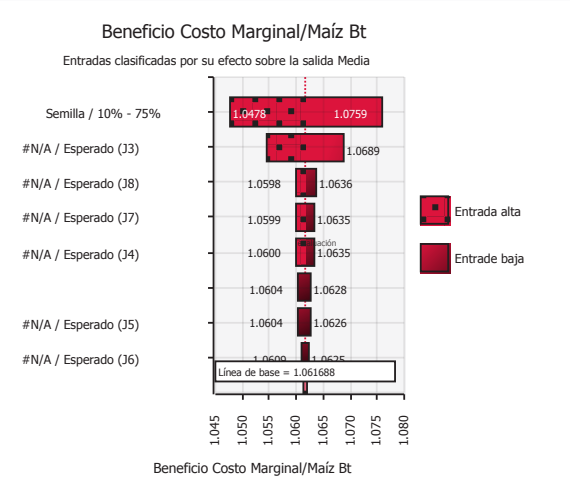

\begin{tabular}{l|l|l|l}
\hline \multicolumn{3}{l}{ Cambio en la estadística de salida de Beneficio Costo Margi } \\
\hline Jerarquía & Nombre & Inferior & \multicolumn{1}{l}{ Superior } \\
\hline 1 & Semilla / 10\% - 7 & 1.05 & 1.08 \\
\hline 2 & \#N/A/Esperado & 1.05 & 1.07 \\
\hline 3 & \#N/A/Esperado & 1.06 & 1.06 \\
\hline 4 & \#N/A/Esperado & 1.06 & 1.06 \\
\hline 5 & \#N/A/Esperado & 1.06 & 1.06 \\
\hline 6 & Reducción de ga & 1.06 & 1.06 \\
\hline 7 & \#N/A/Esperado & 1.06 & 1.06 \\
\hline 8 & \#N/A/Esperado & 1.06 & 1.06 \\
\hline & & & \\
\hline & & & \\
\hline & & & \\
\hline & & & \\
\hline
\end{tabular}

Elaboración propia, con el software @Risk 


\section{Informe @RISK Salida para Beneficio Costo Marginal/Papa Cisgénica}

Ejecutado por: Diez, Gómez y Linares

Fecha: viernes, 22 de septiembre de 2017 12:05:07 p.m.

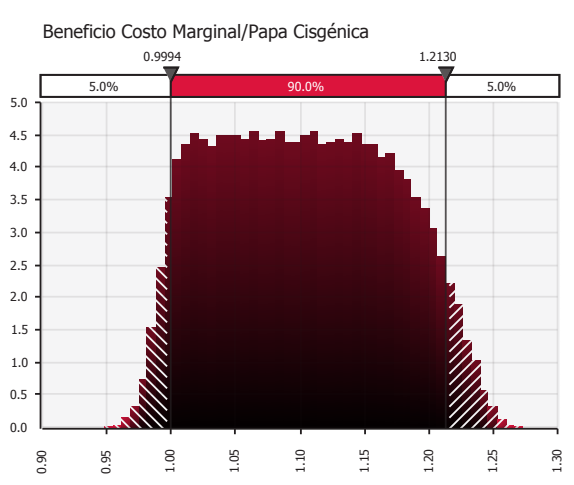

\begin{tabular}{l|l}
\hline Información de resumen de simulación \\
\hline Nombre de libro de trabajo & Libro1 \\
\hline Número de simulaciones & 1 \\
\hline Número de iteraciones & 100000 \\
\hline Número de entradas & 19 \\
\hline Número de salidas & 2 \\
\hline Tipo de muestreo & Latino Hipercúbico \\
\hline Tiempo de inicio de simulación & $22 / 09 / 2017$ 12:01 \\
\hline & $22 / 09 / 2017$ 12:01 \\
\hline Duración de simulación & $00: 00: 15$ \\
\hline Generador de \# aleatorio & Mersenne Twister \\
\hline Semilla aleatoria & 670979581 \\
\hline Total de errores & 0 \\
\hline Recolectar muestras de distribucic Todos \\
\hline Convergencia & Inhabilitado \\
\hline Análisis de sensibilidad inteligent $€$ Habilitado
\end{tabular}

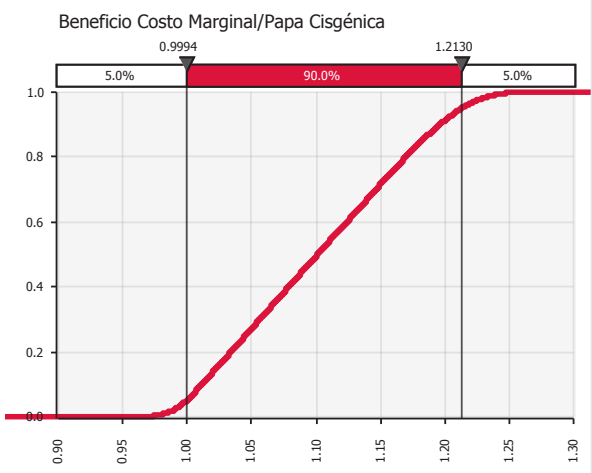

\begin{tabular}{|c|c|c|c|}
\hline Estadísticos re & esumen para Be & eneficio Costo & Papa \\
\hline Estadísticos & & Percentil & \\
\hline Mínimo & 0.95 & $1.0 \%$ & 0.98 \\
\hline Máximo & 1.27 & $2.5 \%$ & 0.99 \\
\hline Media & 1.10 & $5.0 \%$ & 1.00 \\
\hline Desv Est & 0.07 & $10.0 \%$ & 1.01 \\
\hline Varianza & 0.004610807 & $20.0 \%$ & 1.03 \\
\hline Indice de sesgo & 0.089574768 & $25.0 \%$ & 1.05 \\
\hline Curtosis & 1.970095643 & $50.0 \%$ & 1.10 \\
\hline Mediana & 1.10 & $75.0 \%$ & 1.16 \\
\hline Moda & 1.08 & $80.0 \%$ & 1.17 \\
\hline Xizquierda & 1.00 & $90.0 \%$ & 1.20 \\
\hline Pizquierda & $5 \%$ & $95.0 \%$ & 1.21 \\
\hline $\mathrm{X}$ derecha & 1.21 & $97.5 \%$ & 1.22 \\
\hline P derecha & $95 \%$ & $99.0 \%$ & 1.24 \\
\hline \#Errores & 0 & & \\
\hline
\end{tabular}

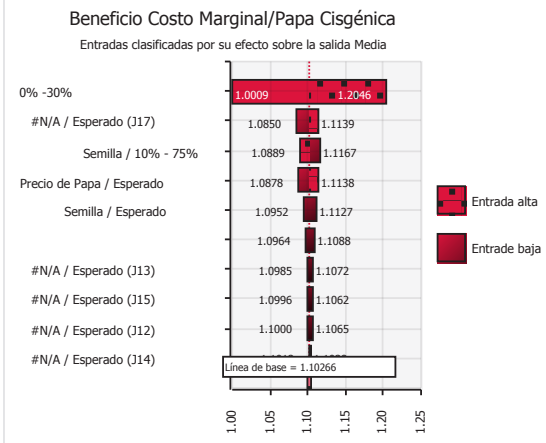

\begin{tabular}{|c|c|c|c|}
\hline Jerarquía & Nombre & Inferior & Superior \\
\hline 1 & Variación de ren & 1.00 & 1.20 \\
\hline 2 & \#N/A/Esperado & 1.08 & 1.11 \\
\hline 3 & Semilla / $10 \%-7$. & 1.09 & 1.12 \\
\hline 4 & Precio de Papa / & 1.09 & 1.11 \\
\hline 5 & Semilla / Esperac & 1.10 & 1.11 \\
\hline 6 & Reducción de ga: & 1.10 & 1.11 \\
\hline 7 & \#N/A / Esperado & 1.10 & 1.11 \\
\hline 8 & \#N/A / Esperado & 1.10 & 1.11 \\
\hline 9 & \#N/A / Esperado & 1.10 & 1.11 \\
\hline 10 & \#N/A / Esperado & 1.10 & 1.10 \\
\hline & & & \\
\hline & & & \\
\hline & & & \\
\hline & & & \\
\hline
\end{tabular}

Elaboración propia, con el software @Risk 


\section{Resultados de entradas de @RISK}

\section{Ejecutado por: Diez, Gómezy linares}

Fecha: viernes, 22 de septienbre de 2017 12:05:16 p.m.

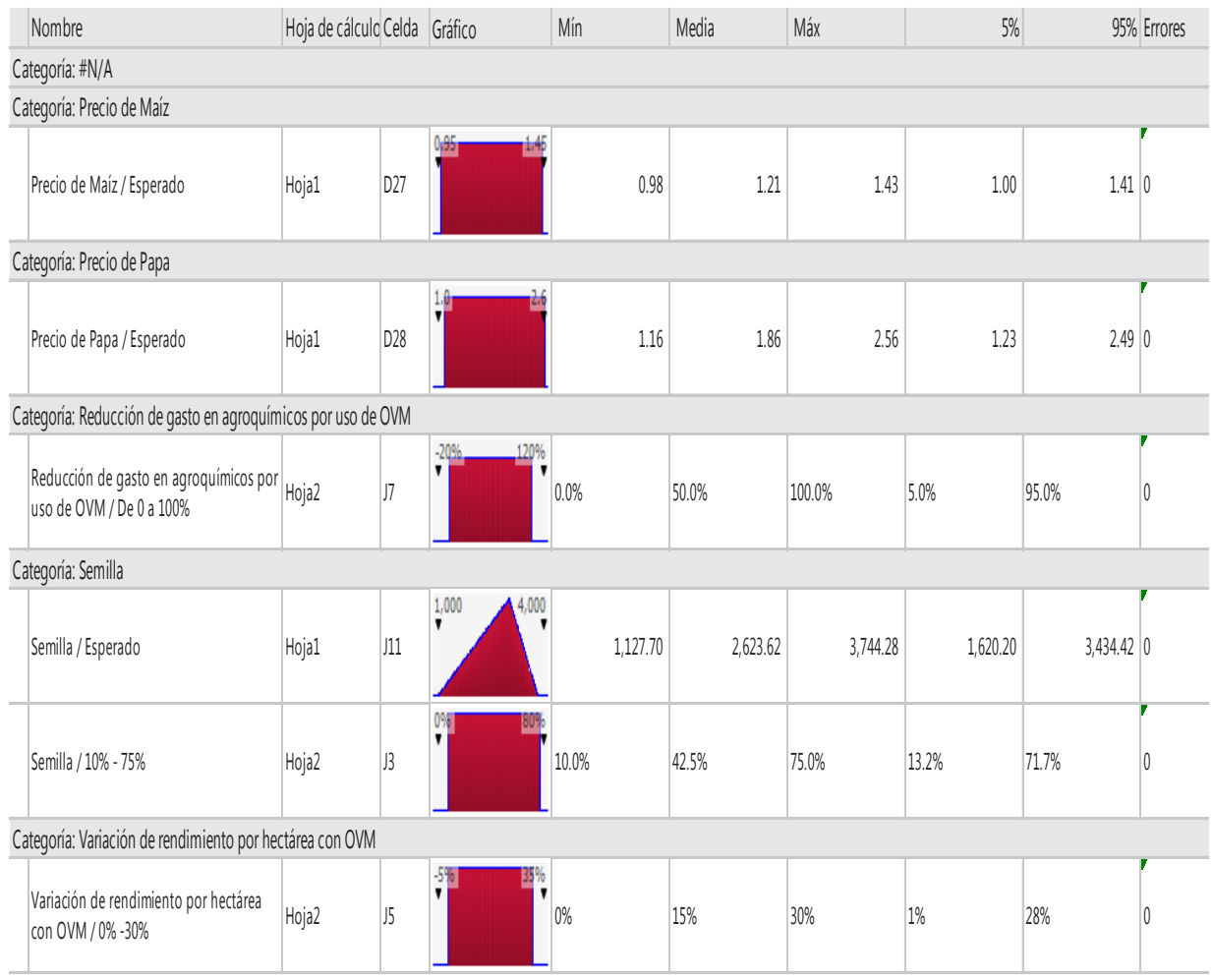

Elaboración propia, con el software @Risk

\section{Resultados de salidas de QRISK}

Ejecutado por: Diez, Gómezy linares

Fecha: verenes, 22 de septientre de 2017 12:05:19 p.m.

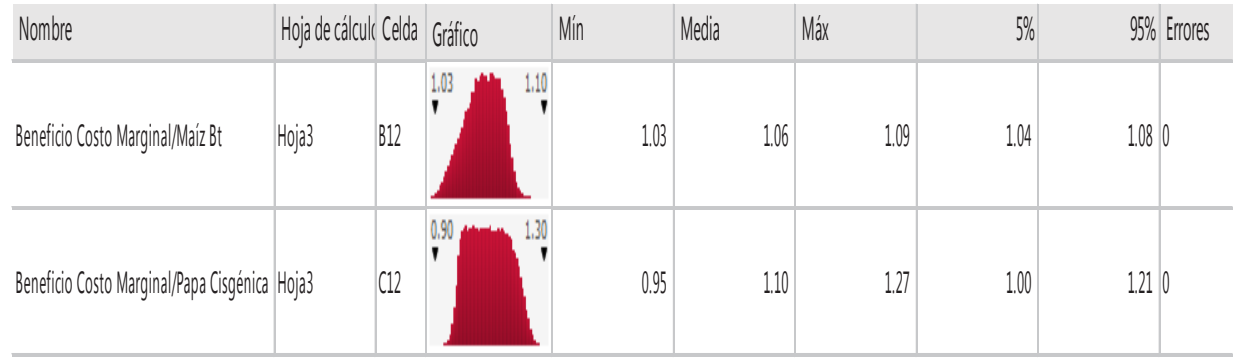

Elaboración propia, con el software @Risk 

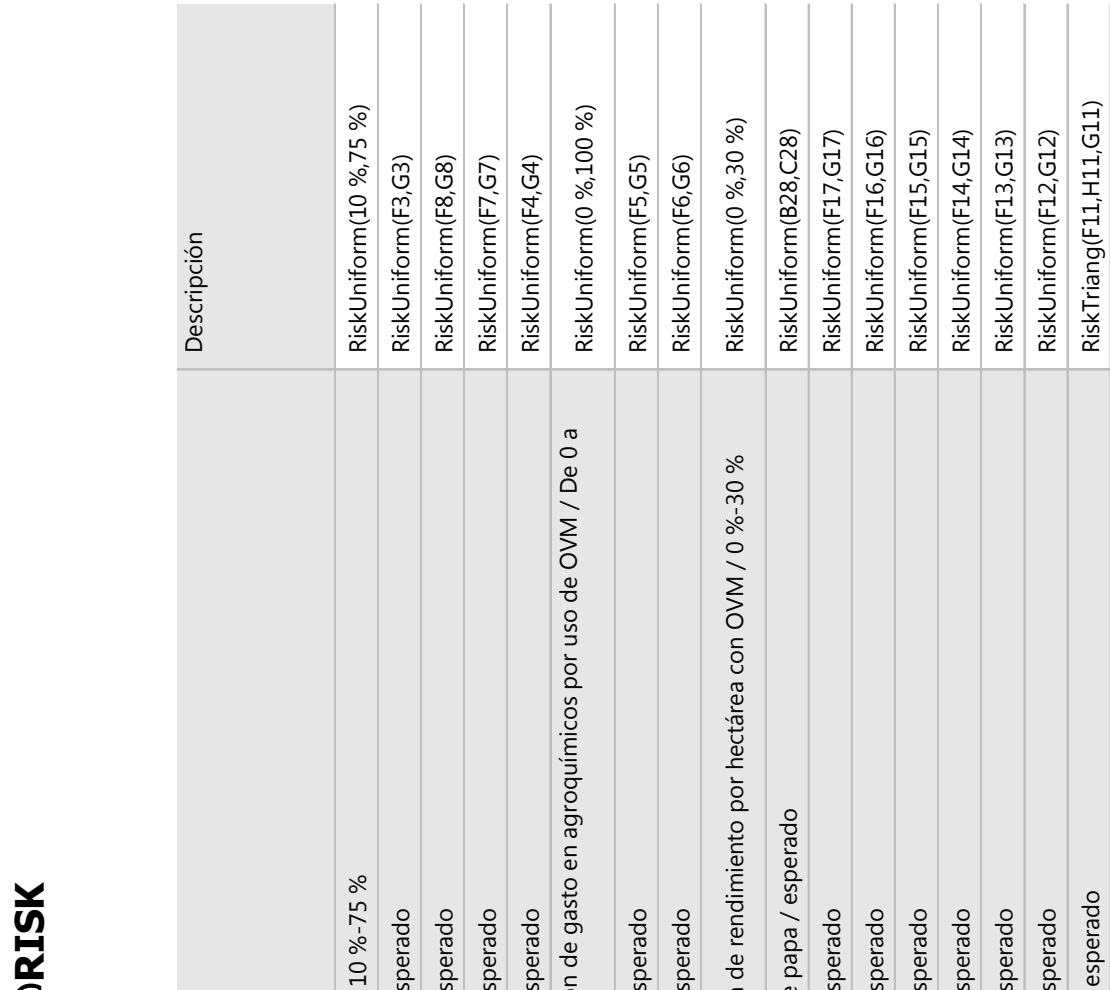

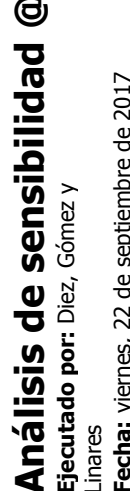

ํํำ

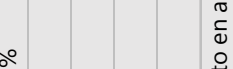

0
0
0
0
$\vdots$
0
0
0
0
0
0
$\vdots$
0
0
0
$\frac{0}{E}$
$\frac{5}{5}$
0
0
0
0
0
0
0

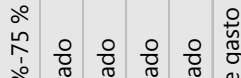

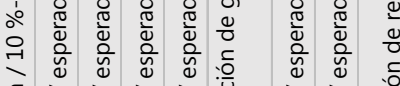

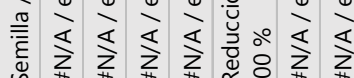

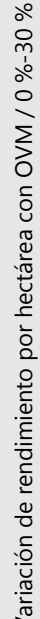

$\frac{0}{\frac{0}{0}}$

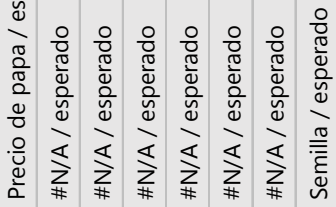

$\frac{\frac{10}{x}}{\frac{10}{2}}$

$\frac{\frac{\pi}{0}}{\frac{0}{4}}$

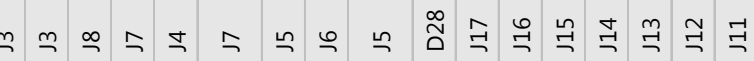

章

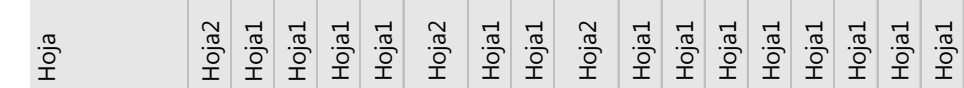

